Валлас Тадеуш,

д-р габілітований,

проф. Університету ім. Адама Міцкевича

(Познань, Польща)
Tadeusz Wallas,

Dr Hab. (Humanities, Politology), Professor of Adam Mickiewicz University of Poznan

(Poznan, Poland)

УДК 007: 304: 001

\author{
МІСЦЕ НАУКИ ПРО КОМУНІКАЦІЮ \\ В КЛАСИФІКАЦІЇ НАУКОВИХ ДИСЦИПЛІН
}

\title{
COMMUNICATION STUDIES IN CLASSIFICATION OF SCIENTIFIC DISCIPLINES
}

\begin{abstract}
Анотація. У дослідженні розглядається питання ролі комунікативістики серед інших наук. Подається опис специфіки науки про комунікацію та можливостей досліджень у цій галузі, як фундаментальних, так $i$ прикладних. Робиться спроба обгрунтувати необхідність розвитку комунікативістики, зважаючи на зростаючі загрози в сучасному суспільстві.

Комунікативістика відповідає основним критеріям, що дозволяють визнати ї повноцінною науковою дисципліною. Пери за все, ия дисципліна має предмет дослідження, що є вивченням того, що пов'язано зі спілкуванням людей і соціальних груп. По-друге, дослідники, що пращюють у галузі дослідження комунікаційних процесів, мають доступ до джерел, які можна збирати, аналізувати і формулювати на їх основі висновки, використовуючи для цього наукові методи і техніки, що є прийнятними для проведення досліджень в сочіальних науках. Підтвердженням тези, згідно з якою наука про засоби масової інформачї є дисципліною сочіальних наук, є міжнародні класифікації. Однією з них є поділ наук Організачією економічного співробітництва та розвитку (ОЕСР) за участю експертів иієї організацї̈ та ЮНЕСКО й Європейського статистичного бюро. Цей поділ сприяє, серед іншого, інтернаціоналізачї наукового співробітничтва.

У поданій прачі подано аргументацію чому комунікативістика є наукою у галузі соціальних, а не гуманітарних наук. Зокрема, в тому, що на відміну від гуманітарних наук, в науках соціальних перевірити гіпотези можна за допомогою експериментів і моделювання. Ще однією тезою дослідження є те, що комунікативістика є міждисциплінарною наукою, що призводить до створення необмежених можливостей генерування нових знань. Ми стоїмо на порозі епохи, в якій найкращі результати наукового пізнання народжуватимуться на основі міждисциплінарних, мультидисциплінарних і трансдисциплінарних зв'язків.

Метою науки є пізнання світу, його законів, що регулюють організацію та функціонування світу. Саме цими завданнями і займається сучасна комунікативістика.
\end{abstract}

Ключові слова: наука про комунікачію, суспільна комунікачія, суспільні науки.

\begin{abstract}
The article attempts to determine the specifics of communication studies, its place and role in the system of scientific disciplines. The author emphasizes the importance of development of this science, especially in today's conditions of constant growth of threats and challenges in the social communication process. The main arguments of the author are as follows: firstly, communication studies will give new opportunities for theoretical and practical study of social communication processes; secondly, in the age of globalization, development of communication studies is a factor for the further development of science in general, as well as social life in all its dimensions. Discussing with the theorists, the author of the article tends in his thoughts to an interpretation proposed by T. Kotarbinski that "the science is any set of human knowledge where one can distinguish the subject of intellectual study and specific specialization" [5].

The specificity of communication studies corresponds to these basic criteria: firstly, it has a relatively defined subject of study and the field of research (all that is related to communication of people and social groups); secondly, for research in this area there is an inexhaustible array of open sources of information; thirdly, there is a developed network of scientific institutions on the basis of which it is possible to develop and implement such researches; fourthly, the advances in the field of communication studies will always have not only theoretical value, but also practical application in the institutions of higher education, where the specialists of corresponding specialization are educated and trained. According to the results of the research, the author comes to the idea that communication studies belong to the sphere of social sciences. For the proof of this concept, the scientist provides for a number of arguments. Keywords: communication studies, social communication, social sciences.
\end{abstract}

Інтегровані комунікації, '1 (5), 2018

() Валлас T., 2018 
$\mathrm{M}$ iejsce nauk o komunikowaniu w klasyfikacjach dyscyplin naukowych. Cel podjętych badań: weryfikacja miejsca nauk o komunikowaniu w nauce; próba określenia specyfiki nauk o komunikowaniu; ukazanie możliwości prowadzenia badań podstawowych, badań stosowanych, a nawet prac wdrożeniowych na gruncie nauk o komunikowaniu; próba uzasadnienia konieczności rozwoju nauk o komunikowaniu $\mathrm{z}$ uwagi $\mathrm{m}$. in. na rosnące zagrożenia $\mathrm{w}$ procesie komunikowania społecznego.

Hipotezy:

- rola i społeczna ocena przydatności nauk o komunikowaniu w oczach kreatorów polityki naukowej, decydentów rozdzielających środki na badania naukowe oraz opinii publicznej wzrośnie w przypadku wykazania możliwości prowadzenia na gruncie tych nauk badań stosowanych;

- w dobie globalizacji rozwój nauk o komunikowaniu jest warunkiem dalszego rozwoju nauki i życia społecznego w różnych jego wymiarach.

Таблиця 1. Systematyka nauk wg Stanisława Kamińskiego

(Zob. szerzej: [1, s. 274])

\begin{tabular}{|l|l|l|}
\hline $\begin{array}{l}\text { Kryterium } \\
\text { podziału: }\end{array}$ & \multicolumn{2}{|c|}{ Nauka } \\
\hline $\begin{array}{l}\text { Źródło } \\
\text { poznania: }\end{array}$ & teologia & wiedza przyrodzona \\
\hline $\begin{array}{l}\text { Zakres } \\
\text { badań: }\end{array}$ & filozofia & nauki szczegółowe \\
\hline $\begin{array}{l}\text { Sposób } \\
\text { wyjaśniania: }\end{array}$ & $\begin{array}{l}\text { nauki formalne } \\
\text { (dedukcyjne) }\end{array}$ & $\begin{array}{l}\text { nauki realne } \\
\text { (indukcyjne) }\end{array}$ \\
\hline $\begin{array}{l}\text { Przedmiot } \\
\text { badań: }\end{array}$ & $\begin{array}{l}\text { przyrodoznawstwo } \\
\text { (nauki } \\
\text { nomologiczne) }\end{array}$ & $\begin{array}{l}\text { przyrodoznawstwo } \\
\text { (nauki } \\
\text { nomologiczne) }\end{array}$ \\
\hline
\end{tabular}

Nauki przyrodnicze badają przyrodę żywą i martwą, umożliwiają poznanie środowiska geograficznego i istot żywych, w tym człowieka od strony fizycznej.

Nauki humanistyczne badają „człowieka społecznego” i wytwory jego kultury.

Dyscyplina naukowa, to wg S. Kamińskiego „logicznie i treściowo zwarta część nauki, jaką - na danym szczeblu jej rozwoju i w określonych warunkach - może jeszcze skutecznie opanować w zakresie twórczych badań oraz dydaktyki jeden pracownik naukowy".

Z kolei A. Chodubski za dyscypliny uznaje "gałęzie nauki wyodrębnione na podstawie kryteriów: przedmiotu nauki, ściśle określonego zakresu, właściwych źródeł i metod badawczych oraz środków działania”

Wg Tadeusza Kotarbińskiego dyscypliną naukową, nazywaną przezeń „nauką jest wszelka całość godna tego, by być przedmiotem nauczania intelektualnego $\mathrm{w}$ szkolnictwie wyższym i dopiero w szkolnictwie wyższym, w charakterze odrębnej specjalności”.
Teza: dyscyplina nauki o komunikowaniu spetnia podstawowe kryteria pozwalające uznać ją za petnoprawna dyscyplinę naukowa.

Po pierwsze, ma ta dyscyplina względnie określony przedmiot i zakres, którym jest badanie tego co związane jest $\mathrm{z}$ komunikowaniem się ludzi i grup społecznych.

Po drugie, badacze operujący w polu badawczym nauk o komunikowaniu mają dostęp do źródeł, które potrafią gromadzić, selekcjonować, analizować oraz formułować na ich podstawie oceny i wnioski, wykorzystując w takim działaniu naukowe metody i techniki właściwe do prowadzenia badań na gruncie nauk społecznych, a także niektórych dyscyplin humanistycznych.

Po trzecie, nauki o komunikowaniu mają coraz bogatsze środki działania. Składają się nań wydziały, instytuty, katedry i zakłady w szkołach wyższych wraz z całym zapleczem kadrowym, bibliotekami, redakcjami czasopism i urządzeniami, jakie do tych jednostek organizacyjnych należą.

Po czwarte, wytwory nauk o komunikowaniu są treściami kształcenia na poziomie szkoły wyższej. Kierunek o takiej nazwie prowadzą prawie wszystkie uniwersytety.

Potwierdzeniem tezy, wg której nauki o mediach są dyscypliną nauk społecznych, są klasyfikacje międzynarodowe. Jedną z nich jest podział nauk dokonany pod patronatem Sekretariatu Generalnego Organizacji Współpracy Gospodarczej i Rozwoju (OECD) z udziałem ekspertów tej organizacji oraz UNESCO i Europejskiego Urzędu Statystycznego [2].

Dostosowane podziału nauki na dyscypliny do klasyfikacji wypracowanej na forum OECD, UNESCO i Eurostatu ułatwia m.in. internacjonalizację współpracy naukowej.

Proponuję przyjąć, że nauki o komunikowaniu to dyscyplina nauk społecznych, którą wyróżnia m. in.:

- większa metodologiczna więź z naukami przyrodniczymi. W naukach społecznych, w porównaniu do dyscyplin n. humanistycznych możliwe jest (w większym zakresie) sprawdzanie hipotez w drodze eksperymentów i symulacji;

- możliwość prowadzenia na ich gruncie badań podstawowych, stosowanych, a nawet prac rozwojowych;

- nastawienie na badanie raczej grup społecznych, współdziałania ich członków w celu uzyskania rezultatu, którego osiągnięcie integruje lub dezintegruje daną grupę, a także poszukiwanie prawidłowości z tym współdziałaniem związanych;

- skupienie się na poszukiwaniu prawidłowości w relacjach między współpracującymi lub rywalizującymi ze sobą grupami społecznymi;

- stawianie akcentów na badanie teraźniejszości i formułowanie prognoz rozwoju życia społecznego.

Specyfiką dziedziny nauk humanistycznych jest $\mathrm{m}$. in.:

- mniejsza metodologiczna więź z naukami przyrodniczymi. Przy weryfikowaniu hipotez w badaniach nad przedmiotem zainteresowania dyscyplin humanistycznych, zdecydowanie mniejszą rolę odgrywają eksperymenty;

Integrated communications, 1 (5), 2018 
- możliwość prowadzenia na ich gruncie badań podstawowych i ostatecznie stosowanych. Prowadzenie prac rozwojowych jest mało prawdopodobne;

- nastawienie raczej na badanie jednostki, jej rozwoju duchowego i uwarunkowań społecznej aktywności takiej jednostki;

- skupienie się na badaniu przede wszystkim wytworów ludzkiego umysłu (np. języka, sztuki, idei) oraz dziejów człowieka społecznego;

- przywiązywanie większej wagi do ustalania faktów, wyjaśniania genezy teraźniejszości i poszukiwanie źródeł dzisiejszych zjawisk w przeszłości.

Таблиця 2.

Klasyfikacja dziedzin nauki i techniki wg OECD - fragment

(Zob. szerzej: [3, s. 303-310])

\begin{tabular}{|c|c|}
\hline Dziedziny nauki & Dyscypliny \\
\hline 5. Nauki społeczne & $\begin{array}{l}\text { 5.1. Psychologia } \\
\text { 5.2. Ekonomia i biznes } \\
\text { 5.3. Pedagogika } \\
\text { 5.4. Socjologia } \\
\text { 5.5. Prawo } \\
\text { 5.6. Nauki polityczne } \\
\text { 5.7. Geografia społeczna i } \\
\text { gospodarcza }\end{array}$ \\
\hline \multicolumn{2}{|l|}{ Dyscypliny } \\
\hline \multicolumn{2}{|c|}{$\begin{array}{l}\text { 5.8 Media i komunikowanie } \\
\text { - Dziennikarstwo; } \\
\text { - Nauka o informacji (aspekty społeczne); } \\
\text { - Bibliotekoznawstwo; } \\
\text { - Media i komunikowanie społeczno-kulturalne; } \\
\text { 5.9 Inne nauki społeczne } \\
\text { - Nauki społeczne interdyscyplinarne. }\end{array}$} \\
\hline Dziedziny nauki & Dyscypliny \\
\hline 6. Nauki humanistyczne & $\begin{array}{l}\text { 6.1. Historia i archeologia } \\
\text { 6.2. Języki i literatura } \\
\text { 6.3. Filozofia, etyka i religia } \\
\text { 6.4. Sztuka (sztuka, historia } \\
\text { sztuki, sztuki sceniczne, } \\
\text { muzyka) } \\
\text { 6.5. Inne nauki humanistyczne }\end{array}$ \\
\hline
\end{tabular}

W odróżnieniu od nauk humanistycznych, na gruncie nauk o komunikowaniu można prowadzić badania (istotę takich badań zdefiniowano na forum OECD):

- badania podstawowe (basic research) to prace eksperymentalne lub teoretyczne podejmowane przede wszystkim w celu zdobycia nowej wiedzy na temat podłoża zjawisk i obserwowalnych faktów bez nastawienia na konkretne zastosowanie lub wykorzystanie w praktyce;

- badania stosowane (applied research) to także oryginalne prace badawcze podejmowane w celu zdobycia nowej wiedzy. Są one jednak ukierunkowane przede wszystkim na osiągnięcie konkretnych celów praktycznych;

Інтегровані комунікації, 1 (5), 2018
- prace rozwojowe (experimental development) to systematyczna praca opierająca się na wiedzy uzyskanej w wyniku działalności badawczej oraz doświadczeń praktycznych i mająca na celu wytworzenie nowych materiałów, produktów, urządzeń lub instytucji inicjowanie/ instalowanie nowych lub znaczące udoskonalenie już istniejących procesów, systemów i usług [Zob. szerzej: 2, s. 89-91].

Przyjmując, że przedmiotem badania będzie np. polityka informacyjna rządu, to celem:

- badań podstawowych nad tym zagadnieniem stanie się opracowanie ocen i wniosków na podstawie analizy porównawczej polityki informacyjnej wybranych państw;

- badań stosowanych będzie zbadanie polityki informacyjnej rządu w Polsce i określenie czynników determinujących jej wysoką skuteczność;

- prac rozwojowych może stać się opracowanie programu polityki informacyjnej rządu w Polsce i sprawdzenie jego efektywności na przykładzie wybranej grupy społecznej.

Pomimo podziałów konstruowanych na różne potrzeby należy jednak pamiętać, że nauka jest też pewną jednością, której fundamentem jest najbardziej ogólny cel jej istnienia i funkcjonowania oraz metoda postępowania.

Celem tym jest poznanie świata, praw oraz prawideł regulujących jego organizację i funkcjonowanie.

Do realizacji takiego celu przyczyniają się także dyscypliny nauk humanistycznych i nauk społecznych.

Interdyscyplinarność w badaniach naukowych jej wielką zasługą jest tworzenie nieograniczonych możliwości generowania nowej wiedzy. Współczesna wiedza, z jej nieustannymi zmianami powiązań pomiędzy polami (obszarami) badań i jej stałym wzajemnym oddziaływaniem na siebie różnych specjalności, $\mathrm{z}$ trudem rozwija się $\mathrm{w}$ ramach tradycyjnych dyscyplin, budowanych za murami specjalizacji i akademickości [Zob. szerzej: 4].

Istotną rolę $\mathrm{w}$ relacjach między badaczami oraz między nimi a potencjalnymi użytkownikami odgrywają wyszukiwarki internetowe, które przy pomocy słów kluczowych, a nie nazw dyscyplin, pozwalają dotrzeć do wiedzy na dany temat wypracowanej na gruncie różnych dyscyplin.

Jesteśmy zatem zapewne na progu epoki, w której najlepsze rezultaty naukowego poznania będą się rodzić na gruncie „interdyscyplin, multidyscyplin i transdyscyplin”.

Celem nauki jest poznanie świata, praw oraz prawideł regulujących jego organizację i funkcjonowanie. Do realizacji takiego celu przyczyniają się także nauki humanistyczne i nauki społeczne.

Dyscypliny wchodzące w skład takich nauk, wg Tadeusza Kotarbińskiego:

„... przygotowują organizację stosunków międzyludzkich i kształtują najogólniejsze dyspozycje człowieka jako istoty gospodarującej i współgospodarującej”. W związku z tym nauki społeczne i humanistyczne, nie są czymś „odrębnym od produkcji” ponieważ są „jej fazą przygotowawczą, jako jej część składowa" [5, s. 48]. 


\section{Список літератури}

1. Źródło: opracowanie własne na podstawie: S. Kamiński, Nauka i metoda. Pojęcie nauki i klasyfikacja nauk, Lublin 1992, s. 274

2. Organizacja Współpracy Gospodarczej i Rozwoju (dalej OECD), Podręcznik Frascati. Proponowane procedury standardowe dla badań statystycznych w zakresie działalności badawczorozwojowej, Ministerstwo Nauki i Szkolnictwa Wyższego 2010, s. 8991, [online] http://www.oecdbookshop.org/get-it.php?REF=5KM7PF D7KSBR\&TYPE=browse 30 VII 2015.

3. Podział dyscyplin na subdyscypliny przedstawiono tylko dla nauk społecznych i humanistycznych. Zob. szerzej: OECD, Podręcznik Frascati ..., s. 303-310.

4. B. R. Kuc, O nauce, dyscyplinach naukowych i kierunkach ich rozwoju, [online] http://wydawnictwoptm.pl/content/8-artykulynaukowe, 11 VIII 2015.

6. T. Kotarbiński, Studia z zakresu filozofii, etyki i nauk społecznych, OSSOLINEUM, Wrocław - Warszawa - Kraków 1970, s. 48 .

\section{References}

1. Kamiński, S. (1992), „Źródło: opracowanie własne na podstawie", Nauka i Metoda. Pojęcie Nauki i Klasyfikacja Nauk,
Lublin, s. 274, available at: http://www.oecdbookshop.org/get-it.php ?REF=5KM7PFD7KSBR\&TYPE=browse.

2. Organizacja Współpracy Gospodarczej i Rozwoju (2010), „Podział dyscyplin na subdyscypliny przedstawiono tylko dla nauk społecznych i humanistycznych", Podręcznik Frascati. Proponowane Procedury Standardowe Dla Badań Statystycznych w Zakresie Działalności Badawczo-Rozwojowej, Ministerstwo Nauki i Szkolnictwa Wyższego, s. 303-310.

3. Organizacja Współpracy Gospodarczej i Rozwoju (2010), Podręcznik Frascati. Proponowane Procedury Standardowe Dla Badań Statystycznych w Zakresie Działalności Badawczo-Rozwojowej, Ministerstwo Nauki i Szkolnictwa Wyższego, s. 89-91, available at: http://www.oecdbookshop.org/get-it.php?REF=5KM7PFD7KSBR\& TYPE=browse $30 \mathrm{VII} 2015$.

4. Kuc, B. R. (2015), O Nauce, Dyscyplinach Naukowych $i$ Kierunkach Ich Rozwoju, available at: http://wydawnictwoptm.pl/ content/8-artykuly-naukowe.

5. Kotarbiński, T. (1970), Studia z Zakresu Filozofi, Etyki $i$ Nauk Społecznych, OSSOLINEUM, Wrocław - Warszawa - Kraków, s. 48.

Подано до редакції 25. 05. 2018 р.

Валляс Тадэуш, д-р габилитованый, проф. Университета им. Адама Мицкевича (Познань, Польша)

\section{МЕСТО НАУКИ О КОММУНИКАЦИИ В КЛАССИФИКАЦИИ НАУЧНЫХ ДИСЦИПЛИН}

Аннотация. В исследовании рассматревается вопрос роли коммуникативистики среди прочих наук. Предоставляется описание специфики науки о коммуникащии и возможностей исследований в этой сфере, как фундаментальных, так и практических. В статье поданы аргументы относительно необходимости развития коммуникативистики, учитывая возростающие угрозы в современном обществе.

Коммуникативистика отвечает основным критериям, ито позволяют признать её полноценной научной дисииплиной. Прежде всего, эта дисииплина имеет предмет исследования, что есть изучением того, что связано с общением людей и сочиальных групп. Во-вторых,исследователи, которые работают в области изучения коммуникационных процессов, имеют доступ к истокам, которые можно собирать, анализировать и формулировать на их основе выводы, используя для этого научные методы и техники, ито приемлимо для проведения исследований в сочиальных науках. Подтверждением тезиса, согласно которому наука о средствах массовой информащии является дисииплиной сощиальных наук, существуют международные классификации. Одной из таких является классификация наук Организацией экономического сотрудничества и развития с участием экспертов этой организащии, а также ЮНЕСКО и Европейского статистического бюро. Эта классификащия способствует, среди прочего, интерначионализации научного сотрудничества.

В представленном исследовании подано аргументащию почему коммуникативистика являэтся наукой в сфере социальных, а не гуманитарных наук. В частности, в том, что в отличии от гуманитарных наук, в науках социальных проверить гипотезы можна с помощью экспериментов и моделирования. Ещё одним тезисом исследования есть то, что коммуникативистика является междисииплинарной наукой, что приводит к созданию неограниченых возможностей генерирования новых знаний. Мы стоим на пороге эпохи, в которой самые лучшие результаты научного познания будут рождаться на основе междисциплинарных, мультидисциплинарных и трансдисциплинарных связей.

Целью науки есть познание мира, его законов, что регулируют организацию и функцьонирование мира. Именно этими заданиями и занимается коммуникативистика.

Ключевые слова: наука о коммуникации, общественная коммуникация, общественные науки. 